\title{
Systematic Innovation Based Design of Energy Efficient House Cooling System
}

\author{
Song-Kyoo Kim, Senior Member, CBEES
}

\begin{abstract}
Energy conservation for buildings is a serious issue for any government and an efficient cooling system of a building in summer is one of major topics for conserving energy. In addition, the resources are very limited in developing countries of tropical regions. The paper deals with the practical approach of enhancing the cooling temperature in the house by the unique problem solving method which is an innovative structured process and sets of practical tools that can be used for the value creation.
\end{abstract}

Index Terms-Energy efficiency, natural cooling, green energy, systematic innovation, low-energy house.

\section{INTRODUCTION}

The whole world is in an endeavor to cope with the impact of climate change. Climate change, especially global heat is mainly caused by human activities such as massive use of natural resources like coal, oil and gas which are then discharged to the atmosphere resulting to an increase in the temperature of the earth. It is not easy to recognize the effects day by day because it takes a long time. People usually just becomes aware when the disasters happens. Climate change is the global issue that every country is affected. Hence, everyone concerned feels it is necessary to solve the problem.

The energy conserving for buildings is serious issue even government [1-3] and efficient cooling system of a building in summer is one of major topics of energy efficient. In addition, the resources are very limited in developing countries. The paper deals with the practical approach of enhancing the cooling temperature in the house by the unique problem solving method. Systematic Innovation is a structured process and set of practical tools that can be used for the value creation. Because of global warming, the summer season especially in tropical region is now longer and higher in degree of temperature [4]. This makes the life of people more uncomfortable and people find many ways to reduce the heat to at least make them feel better. Air Conditioner (AC) can be one of solutions but installation of ACs in the building occur serious harmful side effects:

- The CFC (Chlorofluorocarbon) in AC is harmful to the ozone layer thereby causing global warming.

- $\mathrm{AC}$ consumes more power therefore more negative impact to the environment.

- $\mathrm{AC}$ also causes allergenic dangers to people if there is no timely maintenance.

Manuscript received April 30, 2013; revised July 5, 2013.

Song-Kyoo Kimis with Asian Institute of Management, 123 Paseo de Roxas, Makati City 1260, Philippines (e-mail: SKim@aim.edu).
- A poor people does not have money to buy AC neither to pay for electricity bills.

The initial analysis is shown on Fig. 1. The main reason of this problem is basically the negative impact to environment. The harmful effect of air conditioner is one of main factor of environmental friend house with the energy efficiencies. The unique approaches [5], [6] are applied to solve the issues.

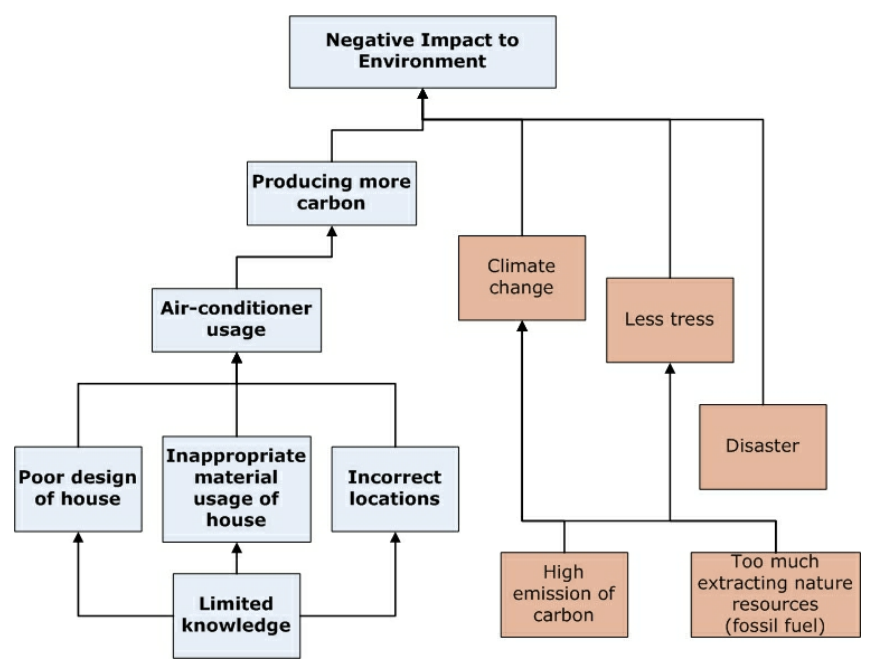

Fig. 1. Analysis of the current cause of cooling system

Systematic innovation [6] is a structured process and set of practical tools can be used to create (or improve) products, process or services that deliver new value to customers. It is also a set of continuous evolving tools that will improve ability to solve the problems. TRIZ [7], [8] is the most powerful methods for systematic innovation methodologies. The substance-field model [7]-[9] and 76 Inventive Standard [5], [10], [11] were conceptualized by the founding father of TRIZ, Genrich Altshuller [1]-[3]. The Standard Solutions are grouped by constraints, so they can help the specialists find appropriate solution concepts [14]. But there are various reasons that the Inventive Standards are not applied widely [15]. Because of the reasons, the special notations so called Su-Field notations (aka. Amang's notations) are introduced. The notations give intuitive explanations both problems and solutions based on the Inventive Standards. The core for Su-Field model notation is adopted by the queuing model notations also kwon as Kendall-Lee notations. Su-Field notations cover all of the Inventive Standards except for Group 5 which is guidelines for other four groups. Someone who does not even have the full knowledge of the 76 Inventive Standard solutions can understand the problems and candidate solutions intuitively based on Su-Field notations. This notation method is clarifying the Inventive 
Standards simpler ways and users can be guided to the candidate solutions from the problems based on Su-Field model with the minimal knowledge of 76 Inventive Standard solutions [15].

\section{Problems of House CoOling System}

The research is targeting to design the energy effective way of cooling inside of houses (or buildings). Green (i.e., eco-friendly) solutions are always welcome and encouraged by the government and many international organizations who work for environment and/or climate change fields. Based on this problem, there are brief guidelines of solutions how to design a natural cooling system that:

- Help people install the auto cooling system that maximizes the use of natural resources and contribute to solve problem of climate change.

- Help people to enjoy the fresh, healthy air at a minimized cost.

- Apply poor friendly and eco-friendly technologies.

- $\quad$ Easy to install and maintenance.

To analyze the problem more clearly, Function Analysis and Root Cause Analysis (RCA) are applied. Based on the formulating the problem, the problem can be defined as follow:

\section{Problems:}

Element: Air (in the house)

Name of Feature: Temperature

Value: $\operatorname{Hot}(>\mathrm{a})$

The final goal is that the air in a house cool enough to stay without any additional resources included in an air conditioner. At the beginning, the problem is about cooling house but it actually about cooling "air" in the house. The next step applies the problem into Function Model (see the Fig. 2).

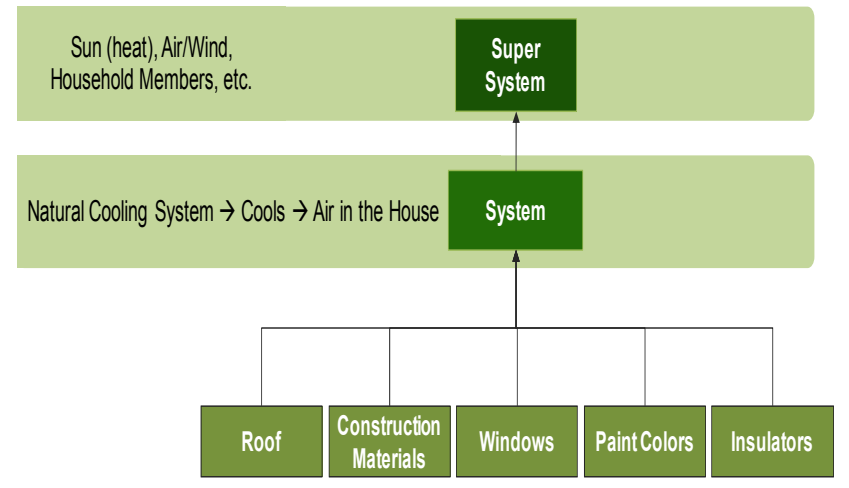

Fig. 2. Function model of cooling house

From the function model, the elements (i.e., sub-system) of the system (home) are as followed Table I:

\begin{tabular}{|c|c|}
\multicolumn{2}{|c|}{ TABLE I: ELEMENTS OF THE FUNCTION } \\
\hline Sub-system & Function \\
\hline Roof & Protection \\
\hline Wall & Enclosure \\
\hline Window & Opening \\
\hline Insulator & Insulation \\
\hline Paint & Color (aesthetics), material protection \\
\hline
\end{tabular}

\section{CONCEPt Solution DESIGN By USING Systematic INNOVATIONS}

\section{A. Enhanced Su-Field Model Summary}

The innovative notation based on Su-Field model (Su-Field notation) is applied [15] and innovative notation schema is classified the Inventive Standards more simple way and users can be guided to the candidate solutions from the problems based on Su-Field model [5, 10, 11] with the minimal knowledge of 76 Inventive Standard solutions. Su-Field Notation is defined as follow:

$$
(a / b / c):(d / e / f)
$$

where the symbols $a, b, c, d, e$ and $f$ stand for basic elements of the model as follows:

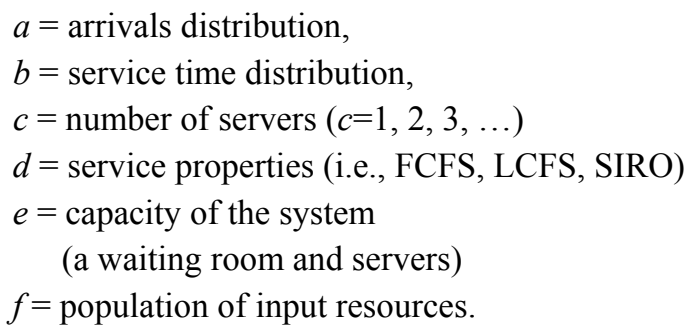

The attributes for fields and substances indicate how to modify the substances and the fields. Su-Field Notation provides a user to be guided even with minimal knowledge of Theory of Inventive Problem Solving (TRIZ) method [16]. The problem solvers can adopt the candidate solutions based on the notations without the full knowledge of 76 Inventive Standard solutions in TRIZ.

\section{B. Problem Clarifications}

The problem for removing of heating can be described as Su-Field Model. Object $\left(S_{1}\right)$ is the air inside of the house which directly affects the temperature of the house. Since the roof is directly acting the air in the house, Tool $\left(S_{2}\right)$ is the roof of house. Based on Su-Field Model, Problem Type-2 [15] as the Su-Field Notation is the problem that contains the harmful action and the candidate solution is basically removing the harmful function:

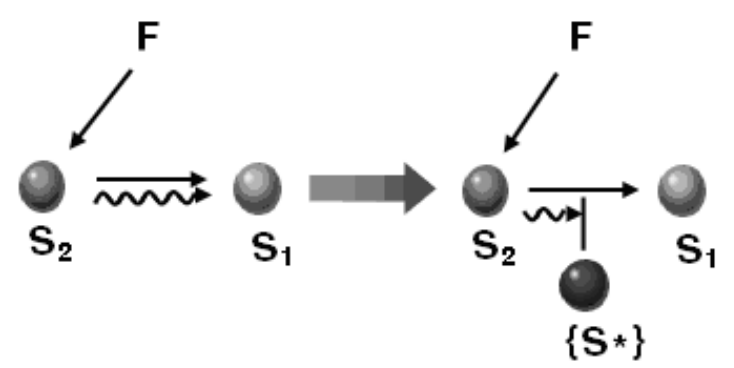

Fig. 3. Candidate solution of problem type-2

From Fig. 3, the candidate solution of Problem Type-2 can be determined as follow [15]:

$$
2 / S / F\{/ 0\} \rightarrow\left\{\begin{array}{l}
2 / S^{*} / F, \quad S^{*}=S^{+} \text {or } S^{\prime} \\
2 / S / F, \\
2 / S / F / a,
\end{array}\right.
$$


where $S^{*}$ and $F^{*}$ are the optimal attributes of the substances and the fields to solve the problem. The typical solution is

$$
2 / S / F\{/ 0\} \rightarrow 2 / S^{\prime \prime} / F
$$

It means that one of substance (typically, Tool is first target to modify) is changed somehow to remove the harmful effect (i.e., heating air in the house).

\section{CONCEPt Design for COOLING AiR}

Based on the concept solution, changing the material and/or colors of the roof are the solutions for removing harmful effect of the system. It can be observed that certain building materials have higher absorption rate of heat and sunlight (see Table II). It increases the overall temperature inside the house. Therefore, one of the recommendation is the roofs that polished copper (18\% absorption) or white asbestos cement (42\%). Thatched roof would make the house more airy if applicable in the house's setting. For the walls, white plaster $(7 \%)$ or white marble $(44 \%)$ would be better options than brick or concrete [2].

TABLE II: ENERGY EFFICIENCY OF MATERIALS

\begin{tabular}{|l|l|}
\hline BUILDING MATERIAL & Absorption (\%) \\
\hline Brick (common) & \\
\hline Light Red & 55 \\
\hline Red & 68 \\
\hline Marble & \\
\hline White & 44 \\
\hline Dark & 66 \\
\hline Polished & $50-60$ \\
\hline Metals & \\
\hline Steel & $45-81$ \\
\hline Galvanized iron, new & 64 \\
\hline Galvanized iron, dirty & 92 \\
\hline Copper, polished & 18 \\
\hline Copper, tarnished & 64 \\
\hline Lead sheet, old & 79 \\
\hline Zinc, polished & 46 \\
\hline Paints & \\
\hline White emulsion & $12-20$ \\
\hline White paint, 4.3 mm on aluminum & 20 \\
\hline White enamel on iron & $25-45$ \\
\hline Aluminum oil base paint & 45 \\
\hline Gray paint & 75 \\
\hline Red oil base paint & 74 \\
\hline Black gloss paint & 90 \\
\hline Green oil base paint & 50 \\
\hline Black paint, 4.3 mm on aluminum & $94-98$ \\
\hline Roofing Materials & 64 \\
\hline Asbestos cement, white & 42 \\
\hline Asbestos cement, 6 months exposure & 61 \\
\hline Asbestos cement, 12 months exposure & 71 \\
\hline Asbestos cement, 6 years exposure & 83 \\
\hline Asbestos cement, red & 69 \\
\hline Tile clay, red & \\
\hline
\end{tabular}

\begin{tabular}{|l|l|} 
Tile & $65-91$ \\
\hline Miscellaneous & \\
\hline Aluminum, polished & 15 \\
\hline Concrete & 60 \\
\hline Concrete, rough & 60 \\
\hline Plaster, white wall & 7 \\
\hline Wood & 60 \\
\hline Asbestos cement board, white & 59 \\
\hline Aluminum foil & 15 \\
\hline Ground Cover & \\
\hline Asphalt pavement & 93 \\
\hline Grass, green after rain & 67 \\
\hline Grass, high and dry & $67-69$ \\
\hline Sand, dry & 82 \\
\hline Sand, wet & 91 \\
\hline Sand, white powdered & 45 \\
\hline Water & 94 \\
\hline Vegetable fields and shrubs, wilted & 70 \\
\hline Common vegetable fields and shrubs & $72-76$ \\
\hline Ground, dry and plowed & $75-80$ \\
\hline Bare moist ground & 90 \\
\hline & \\
\hline
\end{tabular}

Roofs are the first contact of sunlight and dark-colored roofs absorb more heat. As evidence to this, the infrared analysis below shows that black captures the most heat and sunlight. Opt for white (or light colors) instead which is about 20 degrees cooler compared to black. This reduces the overall cooling load of the house (see Fig. 4).

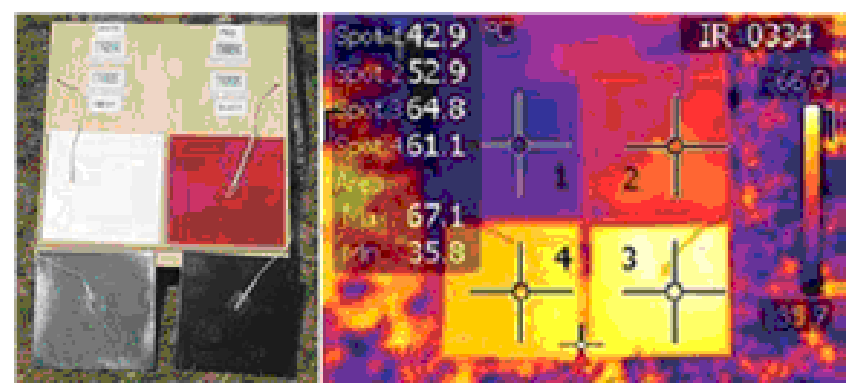

Fig. 4. Temperature differences within colors

Redesigning the shape of the roof is the alternative solution under the same concept solution (i.e., modify the roof). Ventilation techniques are helpful in letting the house breathe (see Fig.5).

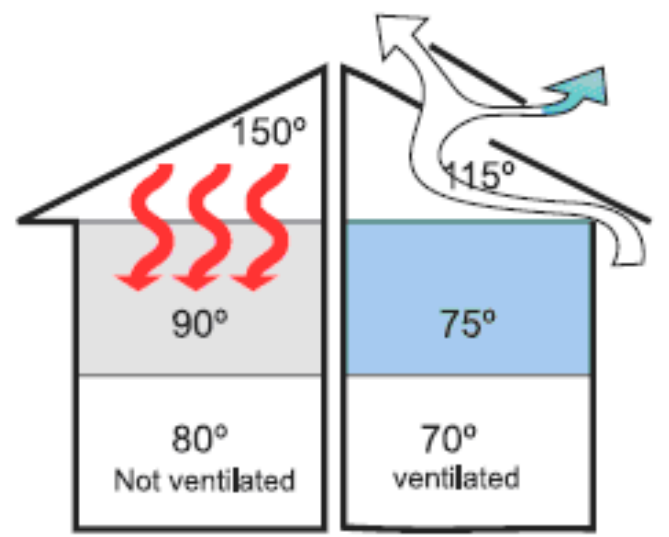

Fig. 5. Temperature differences by shape changes 
Hot air moves up by convection (stack effect) and trapped air causes molds when moisture is created due to condensation. Vents could avert this. They must ideally be installed at opposite sides of the roof eaves (or soffits) to allow cross ventilation.

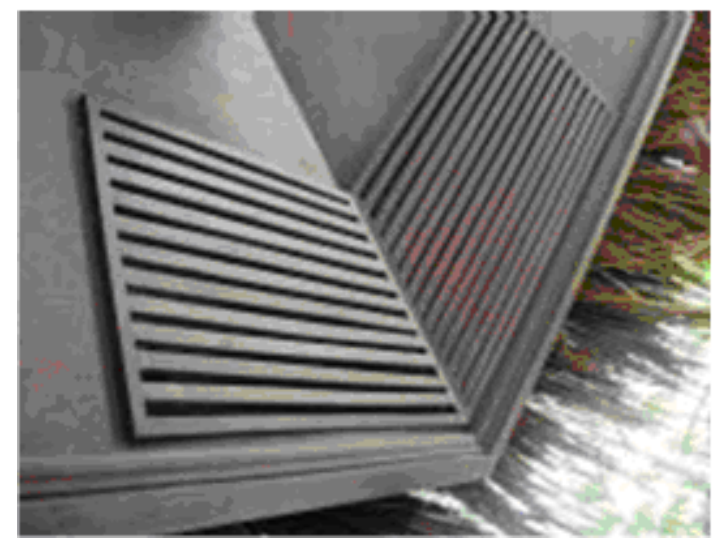

Fig. 6. Actual design of roof shape (inside of house)

\section{CONCLUSIONS}

The problems in this research can be compromised without the use of sophisticated and expensive materials in order to improve and enhance the characteristic of certain equipment which has always been a part of our everyday lives. The major target of the project is developing the energy efficient way for cooling house. The new approach of Systematic Innovation method is applied for solving problems for developing new design. Even though the research is dedicated with environment and civil industries, the pattern of Systematic Innovation approach can be also applied to other industries.

\section{ACKNOWLEDGMENT}

The source of the paper is based on the research project that is the partial requirement to complete the Practical Innovation course for MBA students in Asian Institute of Management. Special thanks to A. F. Felix, J. A. Gaerlan, K. J. Lantican, T. Y. Maung, D. Menon, Y. M. Potnam, N. T. Van who has hardly worked on this project as the team during the course.

\section{REFERENCES}

[1] California Energy Commission, Options for Energy Efficiency in Existing Buildings (2005). [Online]. Available: www.energy.ca.gov/ab549/index.html

[2] Guidelines on Energy Conserving Design of Buildings, Department of Energy, Republic of the Philippines, Energy Center, Fort Bonifacio, Taguig, Philippines (2008)

[3] National Renewable Energy Laboratory, Low-Energy Building Design Guidelines DOE/EE-249, Department of Energy, Golden, CO, USA, 2001.

[4] M. Laar and F. W. Grimme, "Sustainable Buildings in the Tropics," Institute of Technology in the Tropics ITT, University of Applied Sciences Cologne: Presented at RIO-02 World Climate \& Energy Event, January 6-11, 2002.

[5] L. Haijun, "Substance-field Models for Fourth Class Standards," TRIZ Journal, February, 2009.

[6] J. Terninko, A. Zusman et. al., Systematic Innovation: An Introduction to Theory of Inventing Problem Solving, CRC Press, Boca Raton, FL, 1998.

[7] E. Domb, "The Seventy-Six Standard Solutions: How They Relate to the 40 Principles of Inventive Problem Solving," TRIZ Journal, May, 1999.

[8] Grace, Frank et al., "A New TRIZ Practitioner's Experience for Solving an Industrial Problem using ARIZ 85C," TRIZ Journal, January, 2001.

[9] E. Domb, "Using the 76 Standard Solutions: A case study for improving the world food supply," TRIZ Journal, April, 2003.

[10] X. Mao et. al., "Generalized Solutions for Su-Field Analysis," TRIZ Journal, August, 2007.

[11] J. Terninko, "Su-Field Analysis," TRIZ Journal, February (2000)

[12] G. Altshuller, Creativity as an Exact Science, Gordon and Breach Science Publishers, New York, 1984.

[13] G. Altshuller, And Suddenly the Inventor Appeared: TRIZ, the Theory of Inventive Problem Solving, Technical Innovation Center, Worecester, MA, 1996.

[14] G. Altshuller, 40 Principles, Technical Innovation Center, Worcester, MA, 1997

[15] S.-K. Kim," "Concept Design based on Substance-Field Model in Theory of Inventive Problem Solving," International Journal of Innovation, Management and Technology, vol. 3, no. 4, pp. 306-309, 2012.

[16] K. Rantanen and E. Domb, Simplified TRIZ 1st ed., CRC Press, Boca Raton, FL, 2002.

Song-Kyoo (Amang) Kim is an associate professor of Asian Institute of Management. He had been a technical manager and TRIZ specialist of mobile communication division at Samsung Electronics. He is involved in IT industries more than 10 years. Dr Kim has received his master degree of computer engineering on 1999 and Ph.D. of operations research on 2002 from Florida Institute of Technology. He is the author of more than 20 operations research papers focused on stochastic modeling, systematic innovations and patents. He had been the project leader of several 6 Sigma and TRIZ projects mainly focused on the mobile industry. 